\title{
Magnetic records of heavy metal pollution in urban topsoil in Lanzhou, China
}

\author{
WANG Bo ${ }^{1}$, XIA DunSheng ${ }^{1,2 *}$, YU Ye ${ }^{2}$, JIA Jia $^{1} \&$ XU ShuJing ${ }^{1}$ \\ ${ }^{1}$ Key Laboratory of West China's Environmental Systems (Ministry of Education), Lanzhou University, Lanzhou 730000, China; \\ ${ }^{2}$ Key Laboratory of Desert and Desertification, Cold and Arid Regions Environmental and Engineering Research Institute, \\ Chinese Academy of Sciences, Lanzhou 730000, China
}

Received March 29, 2012; accepted June 28, 2012; published online August 18, 2012

\begin{abstract}
This study is a systematic analysis of the magnetic characteristics and heavy metal elements in soil samples collected from Lanzhou City, China. The 117 surface soil samples were measured to study the feasibility and effectiveness of environmental magnetism for evaluating heavy metal pollution in urban soils. Results of the study indicate that low-coercivity magnetite dominates the magnetic properties in the samples. The high values of the soil magnetic mineral concentration parameters and low values of magnetic particle size parameters are distributed throughout the northern area of Xigu District, the industrial zones of the eastern section of Chengguan District and the districts of the narrow sections connecting Chengguan District and the other three districts; these parameters are fundamentally consistent with the distribution of the high values of the Pollution Load Index and Nemerow Pollution Index. Semi-quantitative studies which use the environmental magnetic method to monitor pollution of heavy metals (such as $\mathrm{As}, \mathrm{Cr}, \mathrm{Cu}, \mathrm{Ni}, \mathrm{Pb}, \mathrm{Zn}$, and $\mathrm{Fe}$ ) have shown that when $\chi_{\mathrm{l}} \leqslant 35 \times 10^{-8} \mathrm{~m}^{3} \mathrm{~kg}^{-1}$, it is unpolluted; when $35 \leqslant \chi_{1 \mathrm{I}}<150 \times 10^{-8} \mathrm{~m}^{3}$ $\mathrm{kg}^{-1}$, it is moderately polluted to unpolluted; when $150 \leqslant \chi_{\mathrm{l}}<365 \times 10^{-8} \mathrm{~m}^{3} \mathrm{~kg}^{-1}$, it is moderately polluted; when $365 \leqslant \chi_{11}<750 \times 10^{-8}$ $\mathrm{m}^{3} \mathrm{~kg}^{-1}, \chi_{\mathrm{fd}} \%<2.7$ and $\chi_{\mathrm{ARM}} / \mathrm{SIRM}<0.2 \times 10^{-3} \mathrm{~m} \mathrm{~A}^{-1}$, it is moderately to highly polluted; when $\chi_{\mathrm{lf}} \geqslant 750 \times 10^{-8} \mathrm{~m}^{3} \mathrm{~kg}^{-1}, \chi_{\mathrm{fd}} \%<2.7$ and $\chi_{\mathrm{ARM}} / \mathrm{SIRM}<0.2 \times 10^{-3} \mathrm{~m} \mathrm{~A}^{-1}$, it is highly polluted. The region of moderately to highly polluted distribution is caused by industry and vehicles, showing that the change of pollution in Lanzhou City bears the trend of "vehicle emission + industrial".
\end{abstract}

environmental magnetism, soil pollution, heavy metal, Lanzhou, Pollution Load Index, Nemerow Pollution Index

Citation: Wang B, Xia D S, Yu Y, et al. Magnetic records of heavy metal pollution in urban topsoil in Lanzhou, China. Chin Sci Bull, 2013, 58: 384-395, doi: $10.1007 / \mathrm{s} 11434-012-5404-8$

Anthropogenic activities, especially industrial processes, give rise to harmful emissions containing various magnetic minerals occurring in different amounts. These emissions are absorbed by the soil, sediments and plants through the atmosphere and runoff processes, and then change the circulation and existing conditions of the magnetic materials, therefore these special magnetic characteristics of the modern environment are all marked by human activities. The structure, type, concentration and particle size of these magnetic particles differ from those of the primary and secondary magnetic minerals occurring in the environment [1-7]. Moreover, magnetic particles are associated with elevated metal concentrations [8-14], especially $\mathrm{Cu}, \mathrm{Pb}$ and

*Corresponding author (email: dsxia@ @lzu.edu.cn)
Zn originating from paint, fuel additives, tyres and particulates from moving parts. Most researchers [15-17] consider that the heavy metals caused by combustion, such as copper, chromium, arsenic, zinc and lead, are always accompanied by iron oxide, and magnetic particles are strongly adsorbent and carriers of heavy metals, so the magnetic parameters may be an effective indicator of the content of certain pollutants.

Environmental magnetism has become one of the main focuses of current research in pollution history reconstruction, monitoring the present environmental pollution, and tracing and separating the sources of pollution. The atmosphere [18-21], street dustfall [22-25], soil [1-11], sediment [12-14], leaves [26-29] and tree rings [30] are usually used as the research targets. Analysis is developed from a single 
pollution source to multiple pollution sources and multivariate data analysis, and in some studies semi-quantitative models are created. Low field magnetic susceptibility measurements have been successfully applied to delineate the anthropogenic pollution range, for example, to delineate contaminated areas in the small range [1-3,8-14] of power plants, metallurgical plants, near industrial areas and along highways, etc. Meanwhile, the applications in the larger polluted areas [4-7] of the Ukraine, Britain and other various countries have been proven successful.

Numerous studies regarding magnetic characters in topsoil were performed in eastern China, as well as several in northwestern China. Lanzhou City, as a heavy industrial city, was earlier used to monitor dustfall and street dust via environmental magnetism. Xia [19,20] measured dustfall in Lanzhou during the period of 1997-2007, and concluded that anthropogenic activities (mainly originating from coal burning) were the main sources of urban particulate pollutants occurring in Lanzhou. Wang [23,24] collected street dust samples representing different temporal and spatial scales, and the samples indicated that the concentration of magnetic materials were associated with heavy industry, concentrated residential development and vehicular traffic. Atmospheric dust mainly originates from particulate matter in cities, while street dust and soil possess a range of sources broader than atmospheric dustfall, such as weathering soil, vehicle exhaust emissions, industrial waste gas accumulation, solid waste and rain runoff. The difference between soils and street dust is that street dust does not easily remain in one place for a long period of time and is easily suspended again into the atmosphere. When these street dusts remain in the surface soil, after accumulating for several years, they will remain in the local environment for a long period of time, and will then be transformed through dissolution, precipitation, REDOX and adsorption processes. Therefore, the topsoil in urban areas reflects the local longterm pollution characteristics, or at least pollution characteristics of the past few years. However, little information is available regarding the magnetic characteristics and their relationship with heavy metals of topsoil in Lanzhou. In this paper, the spatial variations of magnetic properties and their relationship with heavy metals were studied using surface soils in Lanzhou, with the goals of discussing the spatial variations of magnetic characteristics and heavy metals, delineating the relationship between magnetic parameters and heavy metals, examining the applicability of magnetic measurements for mapping heavy metals of topsoil, and attempting to establish magnetic diagnosis models for the Lanzhou area.

\section{Materials and methods}

\subsection{Location of sampling area}

Lanzhou City, the main transport junction in northwestern
China, contains many factories including those used for petroleum processing, chemical combination and machine assembly. The Lanzhou Valley is located in northern China at the junction of the Tibetan Plateau, the Alxa Plateau and the Loess Plateau. The distinctive trough-shaped topography, its persistent stable boundary layer, and the large amount of emissions originating from coal-fired factories and vehicle emissions, have led to Lanzhou's poor air and soil quality.

\subsection{Sampling methods}

Soil samples were obtained from along the roads in the urban area of Lanzhou (Chengguan District, Qilihe District, Anning District, and Xigu District). Urban soils are mostly strongly influenced by human activities, always contain a wealth of xenobiotics. In order to ensure the representativeness of the soil samples within a small sampling range, the soil within $10 \mathrm{~m}$ of each sampling point was measured with a Bartington MS2 magnetometer, excluding the outliers of magnetic susceptibility, and soil with relatively homogeneous magnetic susceptibility was selected. A total of 117 representational samples were collected from a depth of 2 $\mathrm{cm}$, and the sample for each soil sampling point was mixed by multi-point acquisition (Figure 1). The sampling points were selected based on the principle of combining the mesh point with the actual situation. The samples were placed in pocket-sized sealable plastic bags with known susceptibility, and were allowed to dry at room temperature, before being measured in the laboratory.

Previous works [31-33] have shown that the characteristics of S0 loess on Jiuzhoutai Mountain are similar to urban soils found in Lanzhou, therefore samples from Jiuzhoutai could be used as a background of Lanzhou. An additional 21 samples were collected for S0 loess in the Jiuzhoutai section at an interval of $5 \mathrm{~cm}$ as the background value for this study.

\subsection{Analysis methods}

After air drying in the laboratory, $5.5 \mathrm{~g}$ of powder from each sample was packed into plastic boxes for the following series of magnetic measurements: low field $(470 \mathrm{~Hz})$ and high field $(4700 \mathrm{~Hz})$ magnetic susceptibility $\left(\chi_{\mathrm{lf}}\right.$ and $\left.\chi_{\mathrm{hf}}\right)$ were measured using a Bartington MS2 magnetometer. The percentage of frequency-dependent magnetic susceptibility $\left(\chi_{\mathrm{fd}} \%\right)$ was calculated on the basis of the following formula: $\chi_{\mathrm{fd}} \%=\left(\chi_{\mathrm{lf}}-\chi_{\mathrm{hf}}\right) / \chi_{\mathrm{lf}} \times 100$. Anhysteretic remanent magnetization (ARM) was measured using a DTECH AF demagnetizer with a peak AF field of $100 \mathrm{mT}$ and a DC bias field of $0.1 \mathrm{mT}$. This study defined the IRM which was performed using $1000 \mathrm{mT}$ as saturation isothermal remanent magnetization (SIRM). IRMs and SIRM were imparted via an MMPM10 pulse magnetizer. All remanence measurements were performed with a Minispin magnetometer. Stepwise 


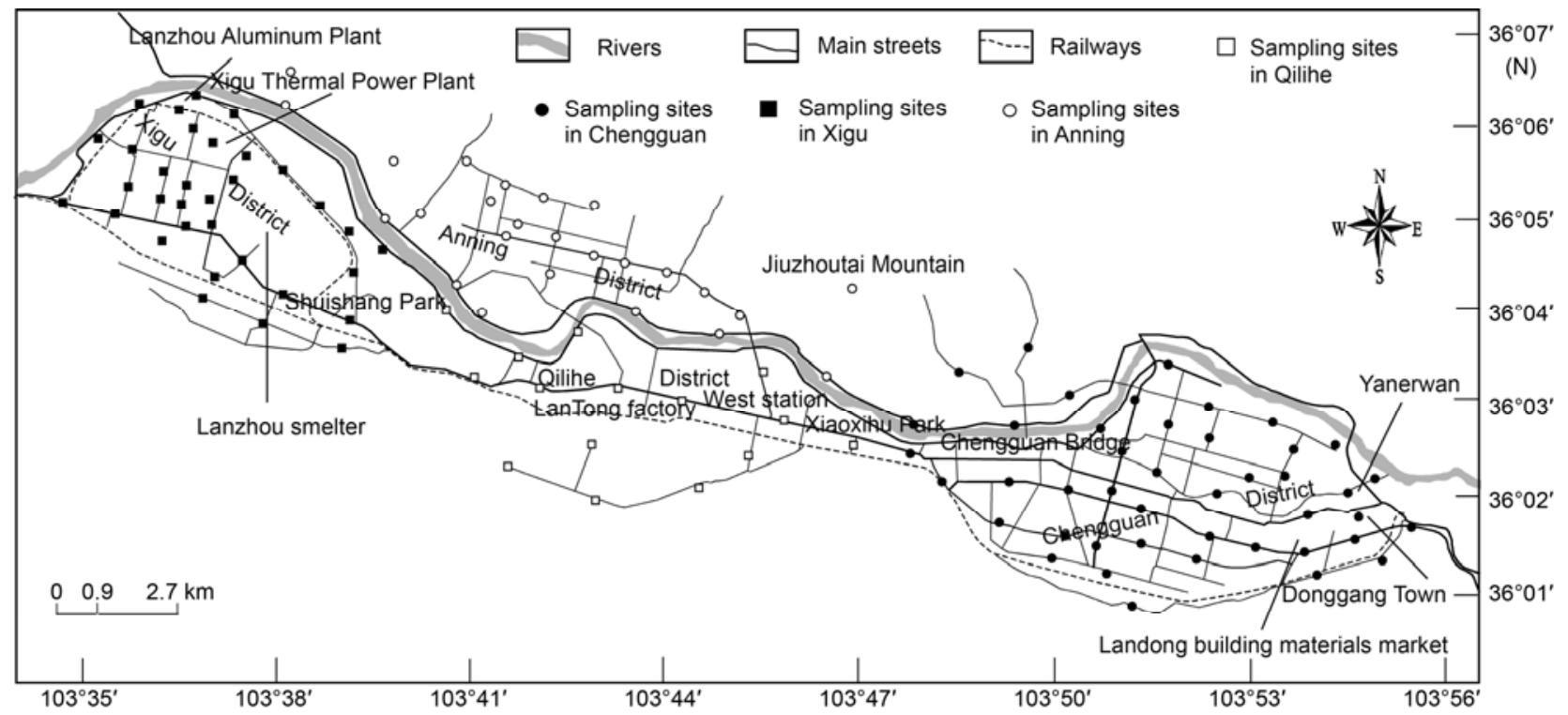

Figure 1 Sketch map depicting soil sampling sites in Lanzhou.

backfield remagnetization of SIRM was performed, the result of which was used to calculate the coercive force of remanence $\left(B_{\mathrm{cr}}\right)$ by means of linear interpolation, as well as to calculate HIRM, SOFT, $\chi_{\mathrm{ARM}} / \mathrm{SIRM}$ and S-ratio $\left(\mathrm{IRM}_{-300 \mathrm{mT}} /\right.$ SIRM). Magnetic hysteresis loops (content $M_{\mathrm{s}}, M_{\mathrm{rs}}, B_{\mathrm{c}}$, maximum field is $1 \mathrm{~T}$ ) and thermomagnetic curves (heating and cooling cycles, which measured from 25 to $700^{\circ} \mathrm{C}$ by $4^{\circ} \mathrm{C} / \mathrm{s}$ in $100 \mathrm{mT}$ magnetic field, were performed in open air) were determined using a variable field translation balance (VFTB). Magnetic parameters were measured in the Key Laboratory of Western China's Environmental System, Lanzhou, China.

The samples were digested in hydrofluoric acid, nitric acid and perchloric acid in polytetrafluoroethylene beakers. The metal concentrations for 6 elements $(\mathrm{Cr}, \mathrm{Cu}, \mathrm{Ni}, \mathrm{Pb}, \mathrm{Zn}$, $\mathrm{Fe})$ were determined using IRIS Advantage ICP-AES after passing through a $0.25 \mathrm{~mm}$ mesh. Heavy metal of arsenic was measured using AFS-9800 Double-way atom fluorescence. During ICP-AES and AFS, $20 \%$ of the samples were randomly selected to conduct parallel double sample testing, in order to ensure that the relative deviation of the measured values of heavy metals was less than $5 \%$. The $20 \%$ of the samples were randomly selected as matrix spiked, and recovery rates were controlled at $100 \% \pm 5 \%$. In addition, back-testing was conducted after testing of every 5 samples to verify the results. Heavy metal content was measured in the Analysis and Test Center, College of Chemistry and Chemical Engineering, Lanzhou University.

\section{Results}

\subsection{Thermomagnetic properties}

Thermomagnetic curves ( $J-T$ curves), showing the Curie point temperature of magnetic minerals, are useful for determining the composition of mineral phases in soils [34]. Thermomagnetic curves of 4 typical samples are shown in Figure 2. The magnetization reduces steadily during the heating alteration process before $250^{\circ} \mathrm{C}$. There is a clear enhancement of magnetization gradient in the heating alteration process between $250-300^{\circ} \mathrm{C}$, then magnetization decreases slowly; the slope has a clear enhancement between $430-480^{\circ} \mathrm{C}$ in the heating alteration process, with magnetization enhancing occurring in the samples, which may have been influenced by iron silicate minerals or clay minerals (e.g. chlorite) which transform into magnetite [35,36], and this phenomenon is more common in the topsoil samples. A sharp decline in the magnetization occurs after the $500^{\circ} \mathrm{C}$ point, and the magnetization at about $580^{\circ} \mathrm{C}$ has been close to 0 , showing the typical characteristics of the magnetite; the heating curves also reduce steadily during heat alteration between 600 and $680^{\circ} \mathrm{C}$, which indicates that there was a certain amount of hematite present. Moreover, the curves for the heating and cooling processes of Lanzhou soils are non-reversible with the cooling curve being above the heating curve, with a Curie temperature of $580-600^{\circ} \mathrm{C}$, indicating the original prevalent contribution of magnetite and the production of new magnetite grains during the heating process. Therefore, the characters of soil samples in Lanzhou are dominated by magnetite, accompanied with hematite.

\subsection{Hysteresis characters}

Hysteresis is a unique physical phenomenon occurring in ferrimagnetic materials, and is used to describe the relationship between magnetic remanesence obtained in a pulsed direct current magnetic field and the density of the external magnetic field [34]. The shape of the hysteresis 

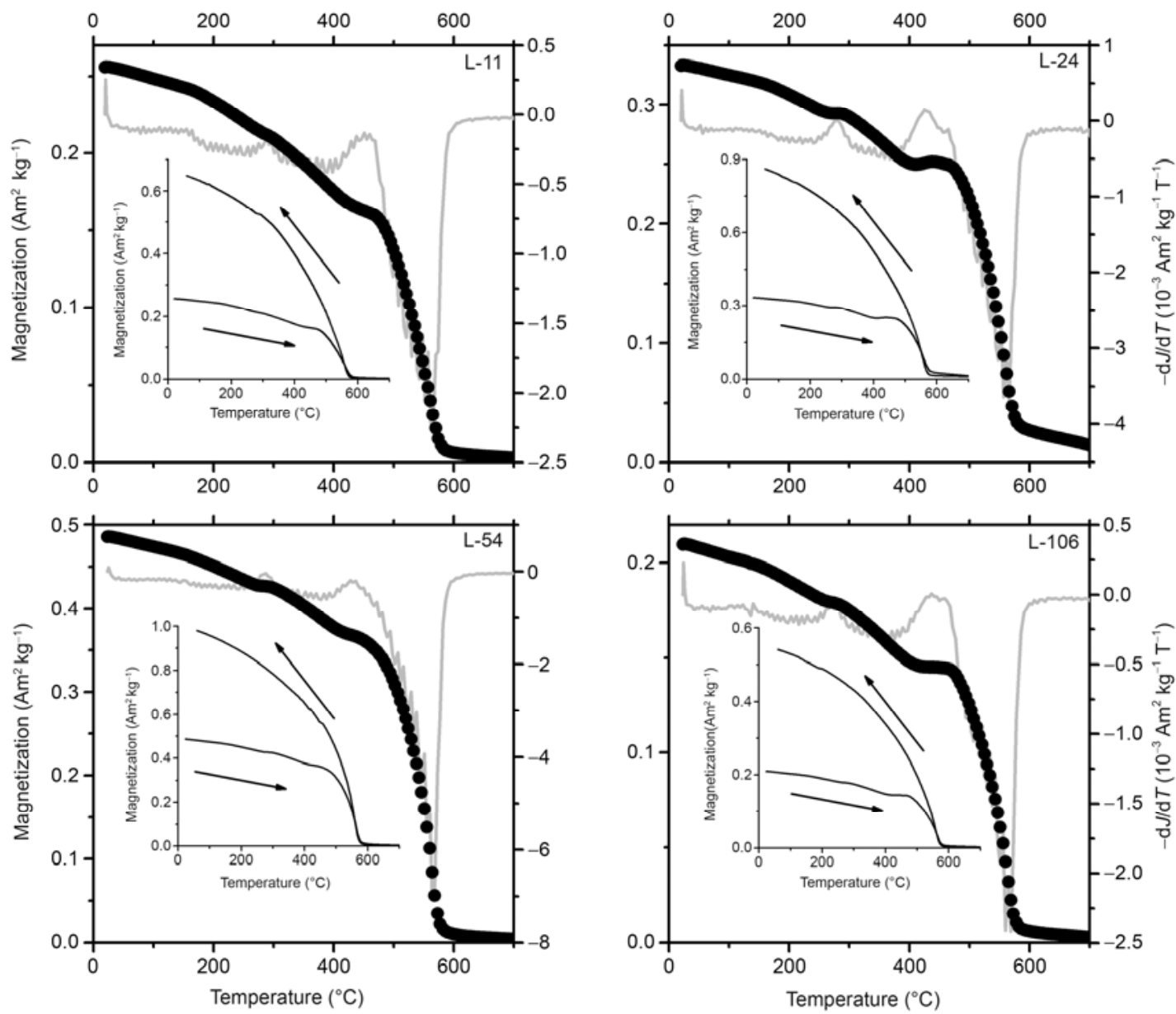

Figure 2 Thermomagnetic curves of typical samples. Black line represents heating processes, gray line represents slope of heating curve. Small figure represents heating and cooling curves. Sample L-11 was taken from Anning District, samples L-24 and L-54 from Xigu District, and samples L-106 from Chengguan District.

loop may be interpreted as a magnetic mineralogical signature, the height of a loop is a function of concentrations and types of magnetic minerals in a natural sample, and the width of a loop is entirely controlled by the coercivity of minerals [37]. Hysteresis loops for typical samples with their corresponding hysteresis parameters are depicted in Figure 3 . The magnetization increases rapidly with the magnetic field strength increase before $200 \mathrm{mT}$. The magnetization almost always saturates when the applied magnetic field reaches $250 \mathrm{mT}$, and the $B_{\mathrm{c}}$ of the representative samples ranges from 9 to $11 \mathrm{mT}$, indicating that the magnetic minerals are dominated by low coercivity ferrimagnets (predominantly magnetite).

\subsection{Spatial distribution of magnetic parameters}

Measurement results are shown in Table 1. Low-frequency magnetic susceptibility $\chi_{\mathrm{lf}}$, the most commonly used magnetic parameter, represents the total contribution of ferrimagnetic minerals $[19,34]$. The samples possessed relatively high mean $\chi_{\mathrm{lf}}$ values of $219.23 \times 10^{-8} \mathrm{~m}^{3} \mathrm{~kg}^{-1}$, ranging from 36 to $649 \times 10^{-8} \mathrm{~m}^{3} \mathrm{~kg}^{-1}$, higher than the background $\left(\chi_{\mathrm{lf}}\right.$ is $35 \times 10^{-8} \mathrm{~m}^{3} \mathrm{~kg}^{-1}$ ), demonstrating that magnetic minerals become enriched to different degrees. Figure 4(a) further shows that $\chi_{\mathrm{lf}}$ is high in following four areas: (1) Lanzhou aluminum plant power and Xigu thermal power plant. (2) Yanerwan, LanDong building materials market enterprise and leather factory. (3) Long and narrow stripe region of materials market-West Station-Xiaoxihu Park-Chengguan Bridge. (4) The area surrounding Shuishang Park. Anning District (especially Jiuzhou Developmental Zone) and south of Qilihe District show low $\chi_{\mathrm{lf}}$ values.

$\chi_{\mathrm{ARM}}, \mathrm{SIRM}$ and SOFT are also related to magnetic mineral content and magnetic particle size [15,34]. SIRM is related to the concentration of magnetic minerals which carry remnent magnetizations, and is largely controlled by ferrimagnetic and canted-antiferromagnetic minerals without the influence of paramagnetic and diamagnetic materials [34]. SOFT [34] approximately reflects magnetite content, particularly the contribution of magnetic grains at the multidomain (MD) range and the SP/SSD border, with low coercive force, while the content of stable single domain (SSD) and pseudo-single domain (PSD) ferrimagnetic grains may be estimated using $\chi_{\text {ARM }}[34]$. HIRM estimates antiferromagnetic 

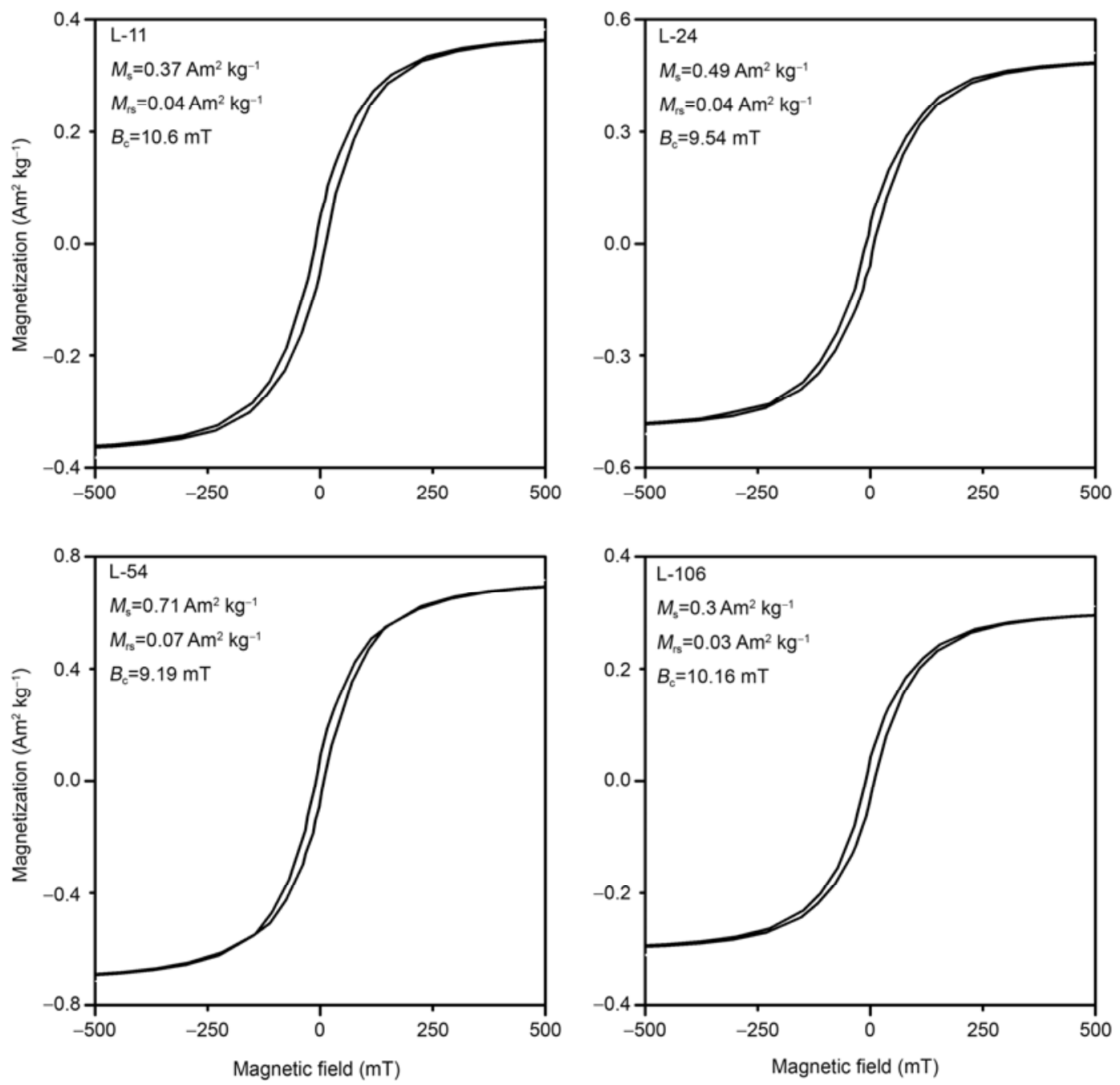

Figure 3 Magnetic hysteresis loop of typical samples. Sample L-11 was taken from Anning District, samples L-24 and L-54 from Xigu District, samples L-106 from Chengguan District.

Table 1 Magnetic parameter values of soil samples found in Lanzhou $(n=117)$

\begin{tabular}{|c|c|c|c|c|c|c|c|c|c|c|}
\hline & $\begin{array}{c}\chi_{\mathrm{lf}} \\
\left(10^{-8} \mathrm{~m}^{3} \mathrm{~kg}^{-1}\right)\end{array}$ & $\chi_{\mathrm{fd}} \%$ & $\begin{array}{c}\text { SIRM } \\
\left(10^{-5} \mathrm{Am}^{2} \mathrm{~kg}^{-1}\right) \\
\end{array}$ & $\begin{array}{c}\chi_{\mathrm{ARM}} \\
\left(10^{-8} \mathrm{~m}^{3} \mathrm{~kg}^{-1}\right) \\
\end{array}$ & $\begin{array}{c}\text { SOFT } \\
\left(10^{-5} \mathrm{Am}^{2} \mathrm{~kg}^{-1}\right)\left(10^{-5}\right.\end{array}$ & $\begin{array}{l}\text { HIRM } \\
\left.-5 \mathrm{Am}^{2} \mathrm{~kg}^{-1}\right)\end{array}$ & $\begin{array}{l}\chi_{\text {ARM }} / \mathrm{SIRM} \\
\left(10^{-3} \mathrm{~m} \mathrm{~A}^{-1}\right) \\
\end{array}$ & $\chi_{\mathrm{ARM}} / \chi$ & $\begin{array}{c}B_{\mathrm{cr}} \\
(\mathrm{mT})\end{array}$ & $S$-ratio \\
\hline Mean & 219.23 & 2.20 & 2508.30 & 422.80 & 753.22 & 83.46 & 0.18 & 2.10 & 40.78 & 0.93 \\
\hline Max & 649.50 & 4.94 & 9129.42 & 1157.15 & 3299.12 & 502.53 & 0.38 & 3.81 & 51.94 & 0.97 \\
\hline Min & 36.73 & 0.25 & 420.67 & 58.30 & 99.88 & 23.53 & 0.07 & 0.78 & 26.65 & 0.85 \\
\hline Background $^{\text {a) }}$ & 35.00 & 3.14 & 377.60 & 109.52 & 100.79 & 21.48 & 0.29 & 3.09 & 54.95 & 0.88 \\
\hline
\end{tabular}

a) The mean value of S0 loess in the Jiuzhoutai section regards as background.

components in a sample. SIRM (Figure 4(b)), $\chi_{\text {ARM }}$ (Figure 4(c)), SOFT (Figure 4(d)) and HIRM (Figure 4(e)) have variations which are similar to $\chi_{\text {If. }}$

$\chi_{\mathrm{fd}} \%, \chi_{\mathrm{ARM}} / \chi_{\mathrm{If}}, \chi_{\mathrm{ARM}} / \mathrm{SIRM}$ relate to the magnetic particle size $[15,34,38]$. The percentage of frequency-dependent susceptibility $\chi_{\mathrm{fd}}[15,34,38]$ relates to the grains of superparamagnetic (SP) ferrimagnetic components, particularly the proportion of fine viscosity particles near the boundary of SSD. A common feature among magnetic particles con- tained in soils is that they all possess low values of $\chi_{\mathrm{fd}} \%$ (mean value of $2.2 \%$, all values below $5 \%$ ), which indicates that magnetic grains in SP state do not significantly contribute to the magnetic component. The high value of $\chi_{\mathrm{fd}} \%$ (Figure 4(f)) is distributed throughout Anning District and the northern area of Qilihe District, which have a contrary distribution with $\chi_{\mathrm{If}}$. When the magnetic mineralogy is homogeneous, $\chi_{\mathrm{ARM}} / \chi$ and $\chi_{\mathrm{ARM}} / \mathrm{SIRM}$ ratios indicate the variation of the grain size of the magnetic minerals $[5,15,34]$. 

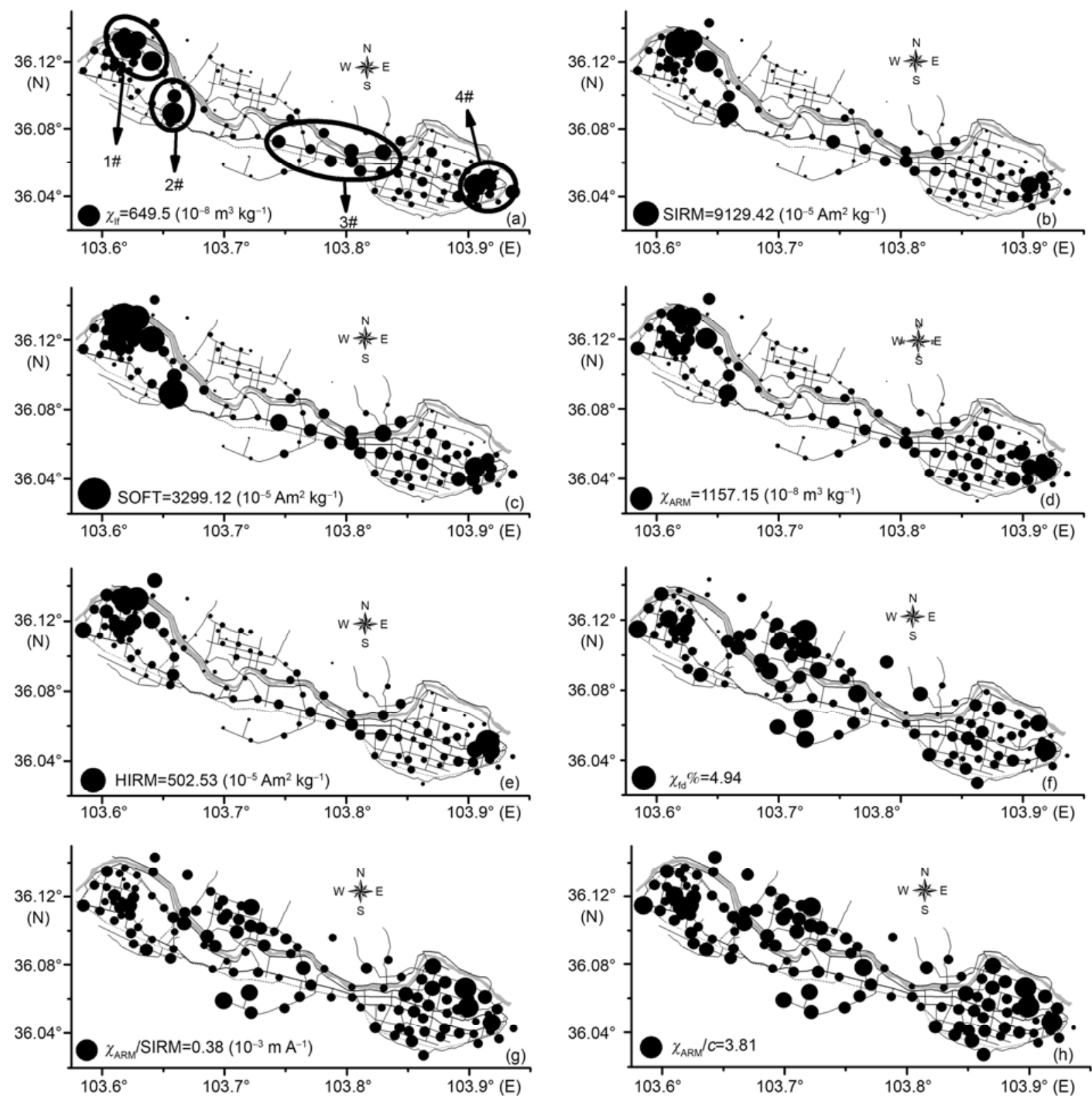

Figure 4 Spatial variation of magnetic parameters, the largest black dot represents the highest value of the corresponding parameters. The areas defined by black lines are as follows: 1\# Lanzhou aluminum plant power and Xigu thermal power plant; 2\# Yanerwan, LanDong building materials market enterprise and leather factory; 3\# long and narrow stripe region of materials market-west station-Xiaoxihu Park-Chengguan Bridge; 4\# the area surrounding Shuishang Park.

In general, both lower $\chi_{\mathrm{ARM}} / \chi$ and $\chi_{\mathrm{ARM}} / \mathrm{SIRM}$ indicate coarse grains of magnetite, while higher ratios indicate fine grains, especially SD grains. The $\chi_{\mathrm{ARM}} / \chi$ ratio depend on the magnetic minerals composition and magnetic particle size $[15,34] . \chi_{\mathrm{ARM}} / \chi$ and $\chi_{\mathrm{ARM}} / \mathrm{SIRM}$ values are 2.1 and $0.18 \times 10^{-3} \mathrm{~m} \mathrm{~A}^{-1}$ respectively, and the values below the background imply the contribution of predominant coarse magnetic particles. $\chi_{\mathrm{ARM}} / \chi$ (Figure $4(\mathrm{~g})$ ) and $\chi_{\mathrm{ARM}} / \mathrm{SIRM}$ (Figure 4(h)) possess variations similar to $\chi_{\mathrm{fd}} \%$.

$S$-ratio represents of the relative amounts of high-coercivity ("hard") remanence to low-coercivity ("soft") rema- nence. In many cases, this allows a fairly accurate estimation of the relative incidence of antiferromagnetic versus ferrimagnetic materials. Samples with a high $S$-ratio primarily contain magnetite; lower values indicate contributions of "harder" magnetic minerals. The mean S-ratio value of the samples is 0.93 , ranging from 0.85 to 0.97 , indicating that the dominant magnetic component is ferrimagnetic minerals. The mean value of $B_{\text {cr }}$ is $40.78 \mathrm{mT}$, ranging from 26.65 to $51.94 \mathrm{mT}$, and the low value of $B_{\text {cr }}$ further indicates that low-coercivity ("soft") minerals (such as magnetite) dominate the magnetic component. 
The above analyses indicate that coarse magnetic particles and ferrimagnetic materials dominate the magnetic minerals found in Lanzhou soils. Highly magnetic minerals are distributed throughout areas associated with heavy industry, concentrated residential development and vehicular traffic.

\subsection{Heavy metal content and pollution evaluation}

Table 2 shows that the mean values of the heavy metals analyzed are higher than the background value, with the exception of nickel. Copper, lead and zinc have high values of $52.41,42.72$ and $184.22 \mathrm{mg} \mathrm{kg}^{-1}$ respectively, which are 2.17, 2.27 and 2.69 times higher than the background value, respectively. These results indicate that each of the heavy metals analyzed shows different degrees of accumulation.

The most popular pollution evaluation methods are the Pollution Load Index and Nemerow Index. The Pollution
Load Index (PLI) [40,41] has been used to obtain concentration factors $\mathrm{CF}=C_{\text {metal }} / C_{\text {backgroud value }}$ for the selected metals. The PLI is then calculated using the n-root from the product of the $n \mathrm{CFs}$ of the metals included:

$$
\mathrm{PLI}=\sqrt[n]{\mathrm{CF} 1 \times \mathrm{CF} 2 \times \mathrm{CF} 3 \times \mathrm{CF} n},
$$

the background value of soil in Gansu Province for each element was used as the background value $C_{\text {backgroud value }}$ Nemerow Index [41] is formulated as follows: $\mathrm{PI}=C_{\text {actual }} /$ $C_{\text {background }} ; \mathrm{P}_{\mathrm{N}}=\left\{\left[\left(\mathrm{PI}_{\text {ave }}{ }^{2}\right)+\left(\mathrm{PI}_{\max }{ }^{2}\right)\right] / 2\right\}^{1 / 2}$, where $\mathrm{PI}_{\text {average }}$ is the average of the sum total of the single pollution index, and $\mathrm{PI}_{\max }$ is the maximum value of the single pollution index. PLI reflects the combined action of many heavy metals, while $P_{N}$ emphasizes the importance of high concentrations of heavy metals. The distribution of PLI shows that bulk samples vary from moderately unpolluted to moderately polluted (Figure 5(a)), and $\mathrm{P}_{\mathrm{N}}$ shows that bulk samples

Table 2 Statistics of heavy metal contents $(n=117)$

\begin{tabular}{|c|c|c|c|c|c|c|c|}
\hline & As $\left(\mathrm{mg} \mathrm{kg}^{-1}\right)$ & $\mathrm{Cr}\left(\mathrm{mg} \mathrm{kg}^{-1}\right)$ & $\mathrm{Cu}\left(\mathrm{mg} \mathrm{kg}^{-1}\right)$ & $\mathrm{Ni}\left(\mathrm{mg} \mathrm{kg}^{-1}\right)$ & $\mathrm{Pb}\left(\mathrm{mg} \mathrm{kg}^{-1}\right)$ & $\mathrm{Zn}\left(\mathrm{mg} \mathrm{kg}^{-1}\right)$ & $\mathrm{Fe}\left(\mathrm{g} \mathrm{kg}^{-1}\right)$ \\
\hline Mean & 20.63 & 93.96 & 52.41 & 38.22 & 42.72 & 184.22 & 33.04 \\
\hline $\operatorname{Max}$ & 46.30 & 549.40 & 136.30 & 100.00 & 77.10 & 509.30 & 44.58 \\
\hline Min & 5.40 & 29.80 & 19.60 & 20.50 & 27.00 & 68.40 & 24.85 \\
\hline Background [39] & 12.60 & 70.20 & 24.10 & 35.20 & 18.80 & 68.50 & 30.90 \\
\hline
\end{tabular}

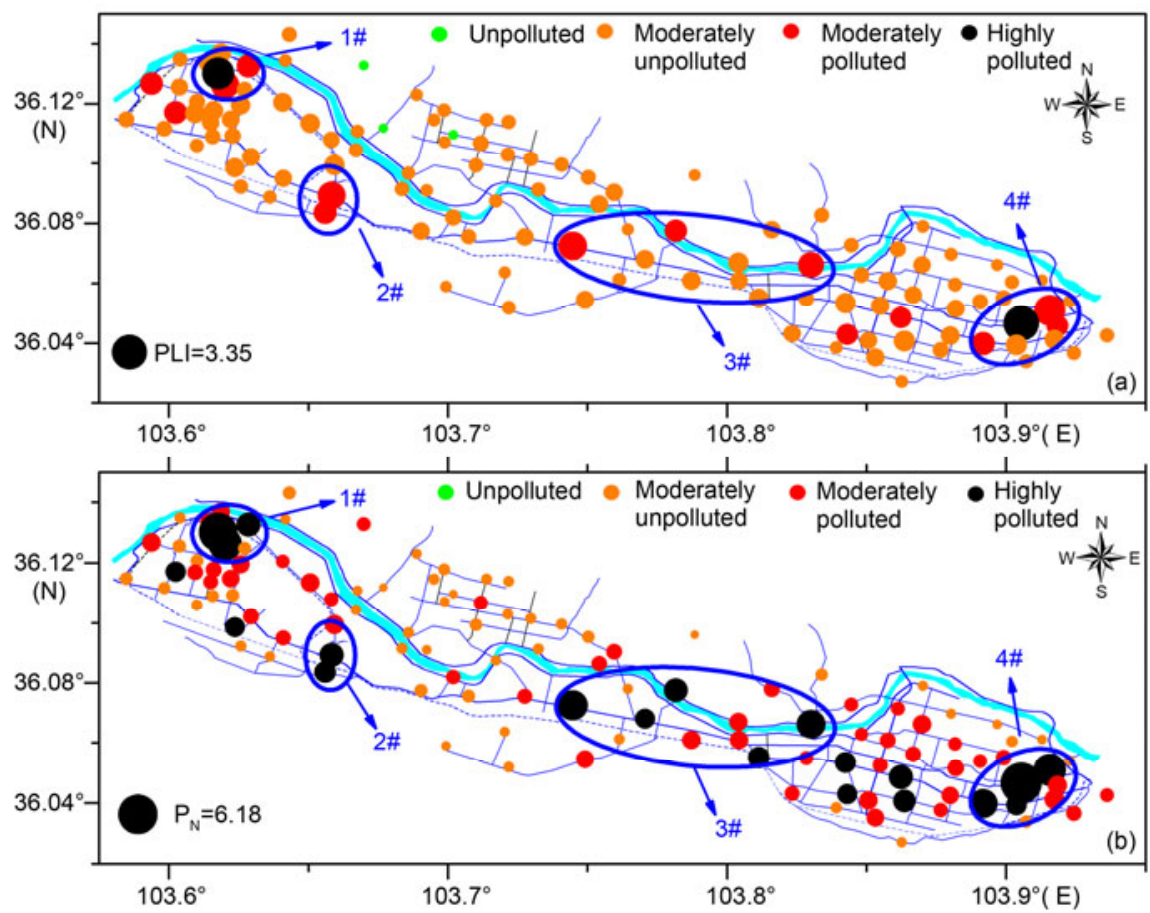

Figure 5 Spatial variation of PLI and $\mathrm{P}_{\mathrm{N}}$, the largest black dot represents the highest value of the corresponding parameters. PLI (or $\mathrm{P}_{\mathrm{N}}$ ) values vary from 0 (unpolluted) to 3 (highly polluted) according to the following scale: $0<\mathrm{PLI}$ (or $\mathrm{P}_{\mathrm{N}}$ ) $<1$ unpolluted; $1 \leqslant \mathrm{PLI}$ (or $\mathrm{P}_{\mathrm{N}}$ ) $<2$ moderately unpolluted; $2 \leqslant \mathrm{PLI}$ (or $\mathrm{P}_{\mathrm{N}}$ ) $<3$ moderately polluted; PLI (or $\left.\mathrm{P}_{\mathrm{N}}\right) \geqslant 3$ highly polluted [40-42]. The areas defined by blue lines are as follows: 1\# Lanzhou aluminum plant power and Xigu thermal power plant; 2\# Yanerwan, Landong building materials market enterprise and leather factory; $3 \#$ long and narrow stripe region of materials marketwest station-Xiaoxihu Park-Chengguan Bridge; 4\# the area surrounding Shuishang Park. 
range from moderately polluted to highly polluted (Figure 5(b)). Although differences exist between PLI and $\mathrm{P}_{\mathrm{N}}$, the two have similar distributions, both showing high values among aluminum plants in Lanzhou, coal-fired power plants in Xigu, Yanerwan, the building materials market and leather factory, and low values in Anning District. Nemerow Index shows that high values are also distributed in Shuishang Park and Panhandle, which are located near the materials market-West Station-Xiaoxihu Park-Chengguan Bridge. These results indicate that the areas which are strongly impacted by human activities, such as industry and vehicles, all face serious pollution problems.

\section{Discussion}

\subsection{Magnetic response of heavy metal pollution}

Heavy metals found in urban soils have been shown to be very useful for tracing environmental pollution. Urban soils are the "recipients" of large amounts of heavy metals originating from a variety of sources including parent materials, industrial waste, vehicle emissions, coal burning and other human activities, and this process often releases a certain amount of magnetic particles. Therefore, magnetics and heavy metal concentrations may be correlated, although several factors may dilute links between the two [15-18]. In order to reveal the characters among each index, in this study principal component analysis (PCA) was applied to identify the source of heavy metals in soil samples, through application of Varimax rotation with Kaiser normalization by SPSS. The results show that there are three factors which account for $74 \%$ of the total variance in the samples. Figure 6 shows that $\chi_{\mathrm{lf}}, \mathrm{SIRM}, \mathrm{SOFT}, \mathrm{HIRM}$ and $\chi_{\mathrm{ARM}}$ are linked to relatively greater ferrimagnetic minerals contributions, along with $\mathrm{As}, \mathrm{Cr}, \mathrm{Cu}, \mathrm{Ni}, \mathrm{Pb}, \mathrm{Zn}$ and $\mathrm{Fe}$ being clustered together, indicating that they are form a symbiosis with one another. Furthermore, Pearson's correlation coefficients between heavy metal concentrations and magnetic parameters are listed in Table 3, and these coefficients suggest that magnetic concentration-related parameters $\left(\chi_{\mathrm{lf}}, \mathrm{SIRM}, \chi_{\mathrm{ARM}}\right.$, HIRM, SOFT) have significant positive correlations with the heavy metals $\mathrm{As}, \mathrm{Cu}, \mathrm{Cr}, \mathrm{Ni}, \mathrm{Pb}, \mathrm{Zn}, \mathrm{Fe}$. Therefore it is shown that mineral content-related parameters may be a suitable and useful index for monitoring heavy metals.

Some studies $[4-6,43]$ consider that the characteristics of anthropogenic pollution combine the high magnetic susceptibility and low percentage of frequency-dependent susceptibility. In this study, although there is a non-significant
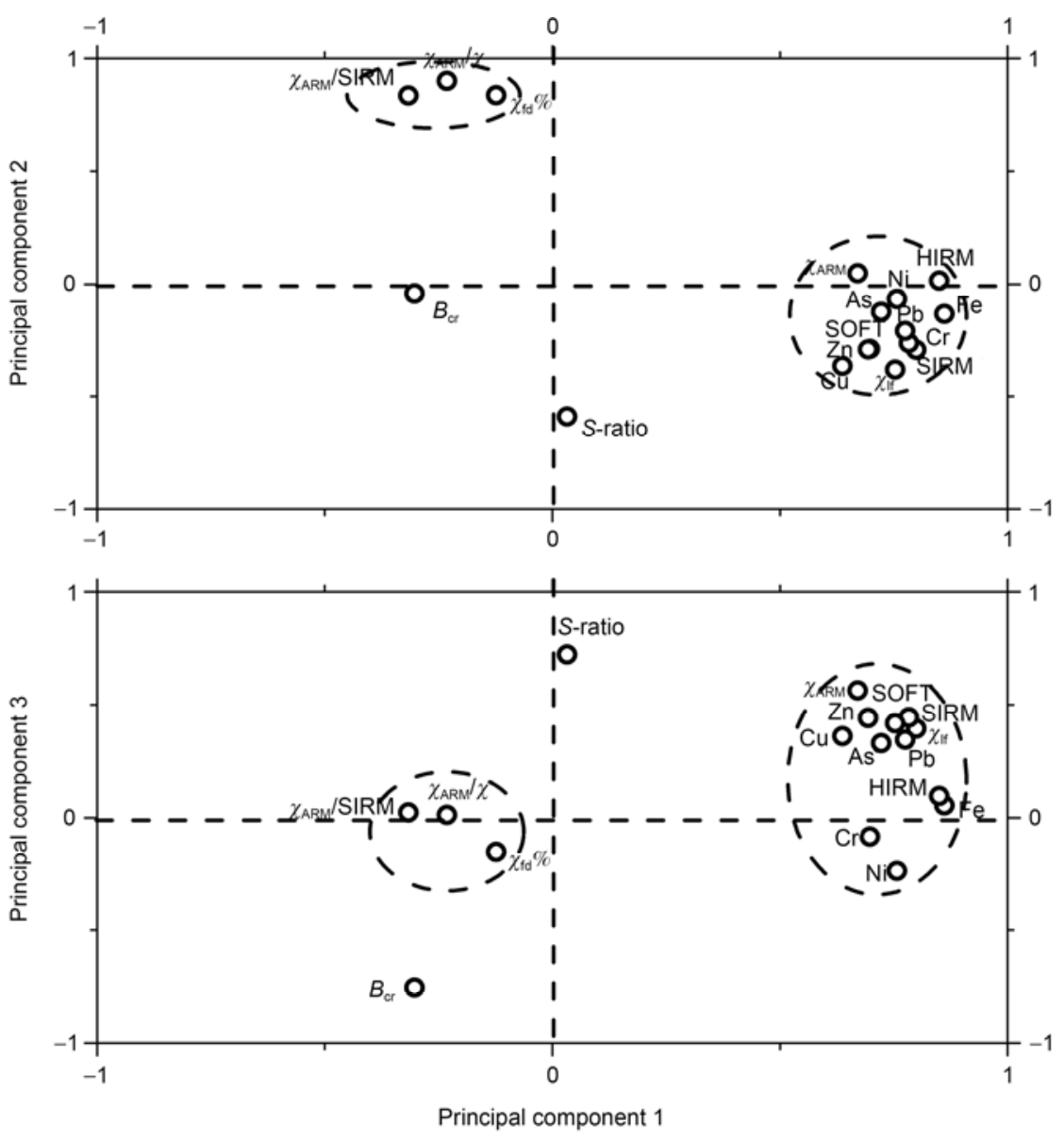

Figure 6 Scatter plot of loadings for principal components 1, 2 and 3. 
Table 3 Pearson correlation coefficients for magnetic properties and heavy metal concentrations of soil samples $(n=117)^{\text {a) }}$

\begin{tabular}{ccccccccccc}
\hline & $\chi_{\mathrm{lf}}$ & $\chi_{\mathrm{fd}} \%$ & $\chi_{\text {ARM }}$ & SIRM & $\chi_{\text {ARM }} /$ SIRM & $\chi_{\text {ARM }} / \chi$ & $B_{\text {cr }}$ & SOFT & HIRM & $S$-ratio \\
\hline $\mathrm{As}$ & $0.639^{* *}$ & -0.161 & $0.541^{* *}$ & $0.637^{* *}$ & $-0.334^{*}$ & -0.301 & $-0.432^{*}$ & $0.649^{* *}$ & $0.509^{* *}$ & $0.334^{*}$ \\
$\mathrm{Cr}$ & $0.645^{* *}$ & -0.286 & $0.395^{*}$ & $0.540^{* *}$ & $-0.331^{*}$ & $-0.396^{*}$ & -0.199 & $0.502^{* *}$ & $0.454^{* *}$ & 0.185 \\
$\mathrm{Cu}$ & $0.721^{* *}$ & $-0.380^{*}$ & $0.579^{* *}$ & $0.653^{* *}$ & $-0.409^{*}$ & $-0.428^{*}$ & $-0.407^{*}$ & $0.637^{* *}$ & $0.430^{*}$ & $0.522^{* *}$ \\
$\mathrm{Ni}$ & $0.452^{* *}$ & -0.120 & $0.361^{*}$ & $0.480^{* *}$ & -0.280 & -0.208 & -0.070 & $0.455^{* *}$ & $0.568^{* *}$ & -0.020 \\
$\mathrm{~Pb}$ & $0.711^{* *}$ & -0.270 & $0.595^{* *}$ & $0.714^{* *}$ & $-0.388^{*}$ & $-0.360^{*}$ & $-0.468^{* *}$ & $0.719^{* *}$ & $0.585^{* *}$ & $0.401^{*}$ \\
$\mathrm{Zn}$ & $0.734^{* *}$ & $-0.376^{*}$ & $0.618^{* *}$ & $0.742^{* *}$ & $-0.439^{* *}$ & $-0.418^{*}$ & $-0.514^{* *}$ & $0.753^{* *}$ & $0.595^{* *}$ & $0.492^{* *}$ \\
$\mathrm{Fe}$ & $0.737^{* *}$ & -0.225 & $0.630^{* *}$ & $0.741^{* *}$ & $-0.344^{*}$ & -0.299 & -0.217 & $0.724^{* *}$ & $0.658^{* *}$ & 0.187 \\
\hline
\end{tabular}

a) * Correlation is significant at the 0.05 level (2-tailed). ** Correlation is significant at the 0.01 level (2-tailed).

correlation between $\chi_{\mathrm{fd}} \%$ and the heavy metals analyzed, the change trends of the two are opposite. Moreover, $\chi_{\mathrm{ARM}} /$ SIRM and $\chi_{\mathrm{ARM}} / \chi$ have a significant negative correlation with analyzed heavy metals, with the exception of nickel, which implies that a correlation exists between magnetic particles and heavy metals: the coarser the particles are, the higher the heavy metal content is.

For soil units, there are two most important sources of magnetic minerals; one is primary, lithogenic minerals, weathering from parent materials, and the other is secondary, pedogenic minerals, weathering from clay minerals resulting from biochemistry activities. In addition, human activities may dramatically influence the magnetic properties of soil in urban areas. Previous investigations have shown that artificial magnetite was characterized by being coarse-grained, and defined it as a sign of the soil being polluted. However, in the western area of China's Loess Plateau, which is dominated by a semi-arid climate, the magnetic property of modern soil is controlled by primary magnetite, which is also coarse-grained and may even be coarser than artificial magnetite [31-33]. Therefore, when the pedogenic intensity of the soil is weak, the heavy metal pollution is more sensitive to the size of magnetic particles than to magnetic mineral concentration. The above results show that the size of the magnetic particles in the Lanzhou soil samples is still of certain significance, but it is not as remarkable as those found in the eastern area.

As depicted above, not only does the magnetic mineral content possess a strong connection with heavy metals, but the magnetic particle size is also closely related with heavy metals. There are different sensitivities among each parameter, for example, the top soils in Lanzhou possess the characteristics of high magnetic susceptibility and coarse magnetic particles. Furthermore, these characteristic-related parameters correspond with the industrial zone and vital communication line. Magnetic parameters $\left(\chi_{\mathrm{lf}}, \mathrm{SIRM}, \chi_{\mathrm{ARM}}\right.$, SOFT) have a strong correlation with PLI and $\mathrm{P}_{\mathrm{N}}$ in determining the bound and level of pollution. The results also suggest that there are close connections between magnetic parameters and heavy metals, and therefore magnetic mineral content-related parameters may be a useful index for determining the bound and level of areas polluted by heavy metals $\mathrm{As}, \mathrm{Cr}, \mathrm{Cu}, \mathrm{Ni}, \mathrm{Pb}, \mathrm{Zn}$ and $\mathrm{Fe}$.

\subsection{Magnetic parameter substitution indexes of semi- quantitative analysis}

As described above, there is a good correlation between topsoil magnetic parameters and heavy metals in soils of Lanzhou City, both have the same source, and the spatial distribution of some magnetic parameters and PLI, $\mathrm{P}_{\mathrm{N}}$ have a high degree of consistency. In order to establish a preliminary quantitative evaluation model by using environmental magnetic parameters to monitor heavy metal pollution, the researchers attempted to study the regression analysis between PLI, $\mathrm{P}_{\mathrm{N}}$ and $\chi_{\mathrm{lf}}, \chi_{\mathrm{fd}} \%, \chi_{\mathrm{ARM}} / \mathrm{SIRM}$ (Figure 7 ). The results showed that the regression equation is $\mathrm{PLI}=$ $0.0026 \chi_{\mathrm{lf}}+1.0498, \mathrm{P}_{\mathrm{N}}=0.0053 \chi_{\mathrm{lf}}+1.2058$. However, the maximum error rate is $30 \%$, so it is not reliable to use the regression equation as the soil pollution degree index, but only as a model to infer the corresponding magnetic susceptibility threshold, for semi-quantitative analysis. The background value of magnetic susceptibility in Lanzhou soil is $35 \times 10^{-8} \mathrm{~m}^{3} \mathrm{~kg}^{-1}$, and this value may be regarded as a clear warning line. The correlation between PLI, $\mathrm{P}_{\mathrm{N}}$ and $\chi_{\mathrm{fd}} \%$ and $\chi_{\mathrm{ARM}} / \mathrm{SIRM}$ is not significant, so the corresponding magnetized rate threshold increased when PLI $>2$ or $\mathrm{P}_{\mathrm{N}}>3$, $\chi_{\mathrm{fd}} \%<2.7$ and $\chi_{\mathrm{ARM}} / \mathrm{SIRM}<0.2 \times 10^{-3} \mathrm{~m} \mathrm{~A}^{-1}$. Finally, the magnetic diagnosis model of soil pollution in Lanzhou area would be established by the combination of both magnetic susceptibility and $\chi_{\mathrm{fd}} \%$, and $\chi_{\mathrm{ARM}} / \mathrm{SIRM}$ under the premise that the samples were dominated by coarse magnetite (Table 4), as follows: when $\chi_{\mathrm{lf}}<35 \times 10^{-8} \mathrm{~m}^{3} \mathrm{~kg}^{-1}$, it is unpolluted; when $35 \leqslant \chi_{\mathrm{lf}}<150 \times 10^{-8} \mathrm{~m}^{3} \mathrm{~kg}^{-1}$, it is moderately polluted to unpolluted; when $150 \leqslant \chi_{\mathrm{lf}}<365 \times 10^{-8} \mathrm{~m}^{3} \mathrm{~kg}^{-1}$, it is moderately polluted; when $365 \leqslant \chi_{\mathrm{lf}}<750 \times 10^{-8} \mathrm{~m}^{3} \mathrm{~kg}^{-1}, \chi_{\mathrm{fd}} \%<2.7$ and $\chi_{\mathrm{ARM}} / \mathrm{SIRM}<0.2 \times 10^{-3} \mathrm{~m} \mathrm{~A}^{-1}$, it is moderately polluted to highly polluted; when $\chi_{\mathrm{lf}} \geqslant 750 \times 10^{-8} \mathrm{~m}^{3} \mathrm{~kg}^{-1}, \chi_{\mathrm{fd}} \%<2.7$ and $\chi_{\mathrm{ARM}} / \mathrm{SIRM}<0.2 \times 10^{-3} \mathrm{~m} \mathrm{~A}^{-1}$, it is highly polluted.

Although the overall trend of the heavy metal content for different pollutants is upward with the increase of magnetic 

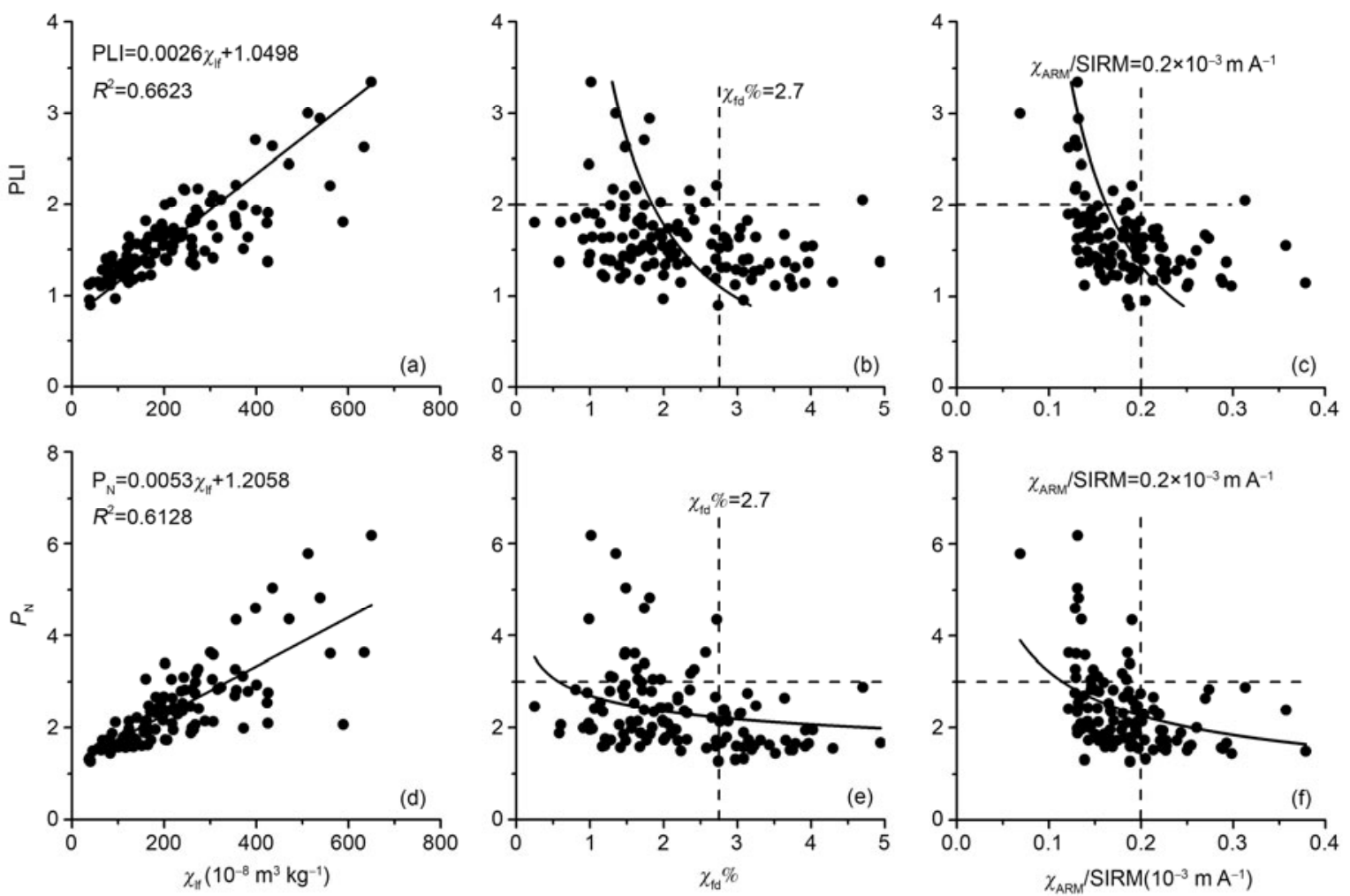

Figure 7 Regression analysis between PLI, $\mathrm{P}_{\mathrm{N}}$ and $\chi_{\mathrm{lf}}, \chi_{\mathrm{fd}} \%, \chi_{\mathrm{ARM}} / \mathrm{SIRM}(n=117)$.

Table 4 Pollution levels according to magnetic parameters

\begin{tabular}{|c|c|c|c|c|c|}
\hline Pollution degree & $\mathrm{PLI} / \mathrm{P}_{\mathrm{N}}$ & Pollution level $^{\text {a) }}$ & $\chi_{\mathrm{lf}}\left(10^{-8} \mathrm{~m}^{3} \mathrm{~kg}^{-1}\right)$ & $\chi_{\mathrm{fd}} \%$ & $\chi_{\mathrm{ARM}} / \operatorname{SIRM}\left(10^{-3} \mathrm{~m} \mathrm{~A}^{-1}\right)$ \\
\hline 0 & $\mathrm{PLI}<1$ and $\mathrm{P}_{\mathrm{N}}<1$ & unpolluted & $\chi<35$ & - & - \\
\hline I & $1 \leqslant \mathrm{P}_{\mathrm{N}}<2$ & moderately polluted to unpolluted & $35 \leqslant \chi<150$ & - & - \\
\hline II & $1 \leqslant \mathrm{PLI}<2$ & moderately polluted & $150 \leqslant \chi<365$ & - & - \\
\hline III & $2 \leqslant \mathrm{PLI}<3$ & moderately polluted to highly polluted & $365 \leqslant \chi<750$ & $\chi_{\mathrm{fd}} \%<2.7$ & $\chi_{\mathrm{ARM}} / \mathrm{SIRM}<0.2$ \\
\hline IV & $\mathrm{PLI} \geqslant 3$ & highly polluted & $\chi \geqslant 750$ & $\chi_{\mathrm{fd}} \%<2.7$ & $\chi_{\mathrm{ARM}} / \mathrm{SIRM}<0.2$ \\
\hline
\end{tabular}

a) Pollution levels are divided according to the threshold of integrated pollution levels of PLI and $P_{\mathrm{N}}$.

susceptibility, their increments are different, such as pollution from iron and steel plants and from traffic [1-3,12-19]. Figure 7(a) and (d) shows that the reference significance reduces and error increases along with the rise in the magnetic susceptibility. Furthermore, $17 \%$ of the samples did not meet the criteria when using the results of Table 4 to check the 117 samples taken from Lanzhou soil, and $70 \%$ of these $17 \%$ samples have magnetic susceptibility values higher than $300 \times 10^{-8} \mathrm{~m}^{3} \mathrm{~kg}^{-1}$. The reason for this is that high values of magnetic susceptibility always occur in areas where industrial concentration and vehicle emissions are abundant. Therefore, when using magnetic susceptibility as a reference parameter to monitor urban heavy metal pollution, it is necessary to effectively distinguish the different types of pollution samples so as to avoid any magnetic measurement errors which may be caused by the different types of pollutants.

\subsection{The main pollution factors of Lanzhou City}

Based on the above analysis, when $\chi>365 \times 10^{-8} \mathrm{~m}^{3} \mathrm{~kg}^{-1}$, $\chi_{\mathrm{fd}} \%<2.7$ and $\chi_{\mathrm{ARM}} / \mathrm{SIRM}<0.2 \times 10^{-3} \mathrm{~m} \mathrm{~A}^{-1}$, the soil from Lanzhou City is moderately polluted to highly polluted. As shown in Figure 4, the high value of the magnetic susceptibility is distributed throughout four areas which mentioned above. Shuishang Park was converted by the Lanlian sewage plant, and the Lanzhou steel plant was originally located near Yanerwan and Donggang Townships; it was relocated away from Lanzhou more than 10 years ago, but its effects still exist today. The region of the northwest materials market-West Station-Xiaoxihu Park-Xiguan-Chengguan Bridge is located in the narrowest section, which connects Chengguan 
District with the other regions, and bears the greatest contribution of vehicle emissions. The possible pollution factor for the region including the northern area of Xigu District and eastern area of Chengguan District is industrial pollution, and that in the region of narrowest section is caused by vehicle emissions. These results are concordant with those of other studies regarding the spatial variation of magnetic characteristics of street dust in Lanzhou. At the same time, Wang et al. [23,24] and Xia et al. [19,20] consider that the temporal variation on the street dust and dustfall show that despite the fact that pollution in winter and spring is still higher than in summer, in recent years, winter pollution has been gradually reducing, and summer pollution has shown little change. A visible change in the source of pollution in Lanzhou City shows a trend of shifting from "coal-burning" to "vehicles + industry".

\section{Conclusions}

(1) The mean value of magnetic susceptibility in Lanzhou is $219.23 \times 10^{-8} \mathrm{~m}^{3} \mathrm{~kg}^{-1}$, and ranges from 36.73 to $649.5 \times 10^{-8} \mathrm{~m}^{3} \mathrm{~kg}^{-1}$. The magnetic characteristics are dominated by low-coercivity magnetite. The high values of PLI and $P_{\mathrm{N}}$ and distribution of some magnetic parameters $\left(\chi_{\mathrm{lf}}\right.$, SIRM, $\left.\chi_{\mathrm{ARM}}, \mathrm{SOFT}, \chi_{\mathrm{ARM}} / \mathrm{SIRM}, \chi_{\mathrm{ARM}} / \chi\right)$ are consistent in industrial concentration, high-density traffic areas and areas involving other human activities. The magnetic mineral content and coarse magnetic particles possess certain advantages in delineating the values of regional contamination.

(2) Environmental magnetic semi-quantitative studies regarding the monitoring of heavy metal (As, $\mathrm{Cr}, \mathrm{Cu}, \mathrm{Ni}, \mathrm{Pb}$, $\mathrm{Zn}, \mathrm{Fe}$ ) pollution in the Lanzhou area have shown the following: when $\chi_{\mathrm{lf}} \leqslant 35 \times 10^{-8} \mathrm{~m}^{3} \mathrm{~kg}^{-1}$, it is unpolluted; when $35 \leqslant \chi_{\mathrm{lf}}<150 \times 10^{-8} \mathrm{~m}^{3} \mathrm{~kg}^{-1}$, it is moderately polluted to unpolluted; when $150 \leqslant \chi_{\mathrm{lf}}<365 \times 10^{-8} \mathrm{~m}^{3} \mathrm{~kg}^{-1}$, it is moderately polluted; when $365 \leqslant \chi_{\mathrm{lf}}<750 \times 10^{-8} \mathrm{~m}^{3} \mathrm{~kg}^{-1} \chi_{\mathrm{fd}} \%<2.7$, and $\chi_{\mathrm{ARM}} / \mathrm{SIRM}<0.2 \times 10^{-3} \mathrm{~m} \mathrm{~A}^{-1}$, it is moderately polluted to highly polluted; when $\chi_{\mathrm{lf}} \geqslant 750 \times 10^{-8} \mathrm{~m}^{3} \mathrm{~kg}^{-1}, \chi_{\mathrm{fd}} \%<2.7$ and $\chi_{\mathrm{ARM}} / \mathrm{SIRM}<0.2 \times 10^{-3} \mathrm{~m} \mathrm{~A}^{-1}$, it is highly polluted, which is under the premise that coarse magnetite particles dominate the samples.

(3) Soil pollution in Lanzhou City is mainly concentrated in the northern area of Xigu District, and scattered throughout the industrial zones of the eastern section Chengguan District and the districts of narrow sections connecting Chengguan District and the other three districts, showing that the pollution in Lanzhou City is gradually shifting to the "vehicle emission+industry" type.

We are grateful to Hu Zheng of College of Chemistry and Chemical Engineering, Lanzhou University for geochemical analysis and three anonymous reviewers for helpful comments. This work was supported by the National Natural Science Foundation of China (41071125 and 40871090) and the Hundred Talents Program of the Chinese Academy of Sciences (O827631002 and 290827631).

1 Kapička A, Petrovský E, Ustjak S, et al. Proxy mapping of fly-ash pollution of soils around a coal-burning power plant: A case study in Czech Republic. J Geochem Explor, 1999, 66: 291-297

2 Flanders P J. Identifying fly ash at a distance from fossil fuel power stations. Environ Sci Technol, 1999, 33: 528-532

3 Durža O. Heavy metals contamination and magnetic susceptibility in soil around metallurgical plant. Phys Chem Earth, 1999, 24: 541-543

4 Jeleńska M, Hasso-Agopsowicz A, Kopcewicz B, et al. Magnetic properties of the profiles of polluted and non-polluted soils. A case study from Ukraine. Geophys J Int, 2004, 159: 104-116

5 Hay K L, Dearing J A, Baban S M J, et al. A preliminary attempt to identify atmospherically derived pollution particles in English topsoils from magnetic susceptibility measurements. Phys Chem Earth, 1997, 22: 207-210

6 Blundell A, Dearing J A, Boyle J F, et al. Controlling factors for the spatial variability of soil magnetic susceptibility across England and Wales. Earth-Sci Rev, 2009, 95: 158-188

7 Blundell A, Hannam J A, Dearing J A, et al. Detecting atmospheric pollution in surface soils using magnetic measurements: A reappraisal using an England and Wales database. Environ Pollut, 2009, 157: 2878-2890

8 Canbay M, Aydin A, Kurtulus C. Magnetic susceptibility and heavy-metal contamination in topsoils along the Izmit Gulf coastal area and IZAYTAS (Turkey). J Appl Geophys, 2010, 70: 46-57

9 Karimi R, Ayoubi S, Jalalian A, et al. Relationships between magnetic susceptibility and heavy metals in urban topsoils in the arid region of Isfahan, central Iran. J Appl Geophys, 2011, 74: 1-7

10 Hanesch M, Scholger R. Mapping of heavy metal loadings in soils by means of magnetic susceptibility measurements. Environ Geol, 2002, 42: 857-870

11 Petrovský E, Kapička A, Jordanova N, et al. Magnetic properties of alluvial soils contaminated with lead, zinc and cadmium. J Appl Geophys, 2001, 48: 127-136

12 Zhang C X, Qiao Q Q, John D A, et al. Assessment of heavy metal pollution from a Fe-smelting plant in urban river sediments using environmental magnetic and geochemical methods. Environ Pollut, 2011, 159: 3057-3070

13 Desenfant F, Petrovský E, Rochette P. Magnetic signature of industrial pollution of stream sediments and correlation with heavy metals: Case study from South France. Water Air Soil Pollut, 2004, 152: 297-312

14 Jordanova D, Veneva L, Hoffmann V, et al. Magnetic susceptibility screening of anthropogenic impact on the Danube River Sediments in Northwestern Bulgaria-Preliminary results. Studia Geophys Geod, 2003, 47: 403-418

15 Evans M E, Heller F. Environmental Magnetism-Principles and Applications of Environmagnetics. New York: Acdemic Press, 2003. 1-299

16 Lauf R J, Harris L A, Rawlston S S. Pyrite framboids as the source of magnetic spheres in fly ash. Environ Sci Technol, 1982, 16: 218-220

17 Boyko T, Scholger R, Stanjek H, et al. Topsoil magnetic susceptibility mapping as a tool for pollution monitoring: Repeatability of in situ measurements. J Appl Geophys, 2004, 55: 249-259

18 Oldfield F, Hunt A, Jones M D H, et al. Magnetic differentiation of atmospheric dusts. Nature, 1985, 317: 516-518

19 Xia D S, Chen F H, Bloemendal J, et al. Magnetic properties of urban dustfall in Lanzhou, China, and itsenvironmental implications. Atmos Environ, 2008, 42: 2198-2207

20 Xia D S, Yang L P, Ma J Y, et al. Magnetic property of Lanzhou dustfall and its implication in urban pollution. Sci China Ser D-Earth Sci, 2007, 37: 1073-1081

21 Muxworthy A R, Schmidbauer E, Petersen N. Magnetic properties and Mössbauer spectra of urban atmospheric particulate matter: A case study from Munich, Germany. Geophys J Int, 2002, 150: 558-570

22 Goddu S R, Appel E, Jordanova D, et al. Magnetic properties of road 
dust from Visakhapatnam (India) - relationship to industrial pollution and road traffic. Phys Chem Earth, 2004, 29: 985-995

23 Wang G, Xia D S, Liu X M, et al. Spatial and temporal variation in magnetic propertiesof street dust in Lanzhou City, China. Chin Sci Bull, 2008, 53: 1913-1923

24 Wang G, Oldfield F, Xia D S, et al. Magnetic properties and correlation with heavy metals in urban street dust: A case study from the city of Lanzhou, China. Atmos Environ, 2012, 46: 289-298

25 Bućko M S, Magiera T, Johanson B, et al. Identification of magnetic particulates in road dust accumulated on roadside snow using magnetic, geochemical and micro-morphological analyses. Environ Pollut, 2011, 159: 1266-1276

26 Hu S Y, Duan X M, Shen M J, et al. Magnetic response to atmospheric heavy metal pollution recorded by dust-loaded leaves in Shougang industrial area, western Beijing. Chin Sci Bull, 2008, 53: $1555-1564$

27 Maher B A, Moore C, Matzka J. Spatial variation in vehicle-derived metal pollution identified by magnetic and elemental analysis of roadside tree leaves. Atmos Environ, 2008, 42: 364-373

28 Zhang C X, Huang B C, Li Z Y, et al. Magnetic properties of highroad-side pine tree leaves in Beijing and their environmental significanc. Chin Sci Bull, 2006, 51: 1459-1468

29 Mclntosh G, Gómez-Paccard M, Osete M L. The magnetic properties of particles deposited on Platanus X Hispanica leaves in Madrid, Spain, and their temporal and spatial variations. Sci Total Environ, 2007, 382: 135-146

30 Zhang C X, Huang B C, John D A, et al. Biomonitoring of atmospheric particulate matter using magnetic properties of Salix matsudana tree ring cores. Sci Total Environ, 2008, 393: 177-190

31 Wang B, Xia D S, Yu Y, et al. Magnetic properties of urban dustfall and its environmental implications (in Chinese). J Lanzhou Univ, 2010, 46: 11-17

32 Wang B, Xia D S, Yu Y, et al. Use of environmental magnetism to monitor pollution in the river sediment of an urban area (in Chinese). Acta Sci Circumst, 2011, 31: 1979-1991

33 Jia J, Xia D S, Wei H T, et al. Magnetic properties of typical paleosol and loess stratum of western Loess Plateau and its signification to paleoclimate (in Chinese). J Lanzhou Univ, 2010, 46: 26-40

34 Thompson R, Oldfield F. Environmental Magnetism. London: Allen \& Unwin, 1986. 1-34

35 Deng C L, Zhu R X, Jackson M J, et al. Variability of the temperature-dependent susceptibility of the Holocene eolian deposits in the Chinese Loess Plateau: A pedogenesis indicator. Phys Chem Earth, 2001, 26: 873-878

36 Liu Q S, Deng C L, Yu Y, et al. Temperature dependence of magnetic susceptibility in an argon environment: Implications for pedogenesis of Chinese loess/palaeosols. Geophys J Int, 2005, 161: 102-112

37 Xia D S, Ma J Y, Wang G, et al. Environmental magnetism concepts and their applications to environmental studies in arid regions, Northwest China (in Chinese). Front Earth Sci, 2006, 13: 168-179

38 Dearing J A, Dann R J L, Hay K L, et al. Frequency-dependent susceptibility measurements of environmental materials. Geophys J Int, 1996, 124: 228-240

39 China Environmental Monitoring Center. Chinese Soil Element Background Values (in Chinese). Beijing: China Environmental Science Press, 1990. 329-483

40 Tomlinson D L, Wilson J G, Harris C R, et al. Problems in the assessment of heavy metal levels in estuaries and the formation of a pollution index. Helgoland Mar Res, 1980, 33: 566-575

41 Angulo E. The Tomlinson pollution load index applied to heavy metal "Mussel-Watch" data: A useful index to assess coastal pollution. Sci Total Environ, 1996, 187: 19-56

42 Nemerow N L. Scientific stream pollution analysis. Script Book Co Washington D C, 1974. 1-358

43 Wang L, Liu D S, Lü H Y. Magnetic susceptibility properties of polluted soils. Chin Sci Bull, 2000, 45: 1723-1726

Open Access This article is distributed under the terms of the Creative Commons Attribution License which permits any use, distribution, and reproduction in any medium, provided the original author(s) and source are credited. 